\title{
ARTICLE \\ The Effect of Pesticide Application on QTLs Controlling Traits in Barley
}

\author{
Samira Bakhtiari, Hossein Sabouri*, Mehdi Mollashahi, Hossein Hosseini Moghaddam \\ Department of Plant Production, Collage of Agriculture Science and Natural Resource, Gonbad Kavous University, \\ Gonbad Kavous, Golestan, Iran
}

\begin{abstract}
Among cereals, barley (Hordeum vulgare L.) ranks fourth in consumption worldwide. Among barley breeding goals, one can refer to gene mapping, studying their inheritance, and saturated genetic linkage maps. Problems with pesticide applications include reduced genetic diversity, reduced nitrogen fixation, and destruction of the habitat of especially endangered species. The effect of pesticide application on the emergence of QTLs expressing traits in experimental barley was investigated using 104 barley F2:4 families from Badia $\times$ Kavir cross. A total of 25 QTLs were mapped for all traits. In nonusing pesticides, 12 QTLs were identified for peduncle length, stem diameter, flag leaf length, and awn length. It was found that qFL-4 has major effects on flag leaf length. For using the pesticide, 13 QTLs were detected that QTLs related to stem diameter, grain weight, flag leaf length explained a high percentage of phenotypic variation. The results of this study showed that pesticide application affects the expression of some genes in barley. Besides, major-effect trait-controller QTLs and their associated markers can be used in marker-assisted selection (MAS) programs.
\end{abstract}

Acta Biol Szeged 64(1):63-71 (2020)

\author{
KEY WORDS \\ barley \\ marker-assisted selection \\ pesticide \\ QTL \\ ARTICLE INFORMATION \\ Submitted \\ 05 May 2020. \\ Accepted \\ 14 July 2020 \\ *Corresponding author \\ E-mail: hossein.sabouri@gonbad.ac.ir
}

\section{Introduction}

Barley (Hordeum vulgare L.,) is a diploid crop with $2 \mathrm{n}$ $=2 \mathrm{x}=14$ chromosomes (Germán et al. 2000). Among cereals, barley ranks fourth after wheat, rice, and corn. However, barley has the first planting in terms of the extent of expansion because it can be cultivated under different climatic conditions (Feug et al. 2006). Over $136 \times 10^{6}$ tons of barley are produced worldwide each year, mainly used for livestock nutrition, and for industrial application (Zong-Yun et al. 2006). Due to the economic importance of barley and the widespread cultivation of this cereal, its breeding is on the agenda of breeders. To accomplish barley breeding goals, gene mapping, a study of their inheritance, and saturated genetic linkage maps were necessary. One of the major challenges of barley breeding programs is determining the inheritance and locus of genes controlling these traits ( $\mathrm{Li}$ et al. 2005; Hassan et al. 2010).

All cereals, including barley and wheat, are exposed to various pests and diseases. A pesticide is a substance or mixture of substances used to prevent, control or reduce pest damage. It can be a chemical compound (synthetic or natural), or a biological agent (biopesticide, e.g., a bacterium) eliminating various pests (e.g., insects, pathogenic microorganisms, weeds, nematodes) of the cultivated plant (Shibamoto and Bjeldanes 2009). Alongside the benefits of the pesticide application, there are problems such as reduced genetic diversity, reduced nitrogen fixation, and destruction of living habitats, especially endangered birds and species. In addition, humans receive pesticides through various means, including food consumption; exposure to food (especially fruits and vegetables) is five times more than other ways, such as air and drinking water (Shokrzadeh and Saravi 2011; Bonnechère et al. 2012). When flour and bread prepared, the amount of pesticides is slightly reduced by the procedure of grinding and baking. The highest residual concentration was observed in bran because most residues of pesticides accumulate in the grain exosporium (Kaushik et al. 2009).

Molecular markers made it possible to generate highdensity genomic (genetic) linkage maps for many plants, including barley. These high-density genetic linkage maps based on molecular markers and QTLs (Quantitative Trait Loci) allow using Marker-Assisted Selection (MAS), and in this way selection is possible in the early generations of a breeding program which highly improves efficiency (Ayoub et al. 2003; Han et al. 1994).

In the study of a barley population derived from Steptoe $\times$ Morex cross, 3 QTLs were identified for grain yield using 15 Restriction Fragment Length Polymorphism (RFLP), 
4 Random Amplification of Polymorphic DNA (RAPD), one microsatellite, and 77 Amplified Fragment Length Polymorphism (AFLP) markers. In the same study, it was found that for plant height, the number of spikelet's per spike and grain weight, there was one QTL on chromosome 3 (Kandemir et al. 2000). By conducting research on germination traits in 85 wheat double haploids lines and their parents, Landjeva et al. (2010) identified 20 QTLs, most of which were clustered on the 1DS chromosome. In a study, the QTLs of some major crop traits in barley, a double haploid barley generation derived from a cross between two six-row barley cultivars (Botania $\times$ Rolfi) were studied and RAPD markers were used to prepare the linkage map. Finally, $654 \mathrm{cM}$ of the genome was covered in this study; 1-7 QTLs were determined for each of the attributes of plant height, spike yield, the weight of one thousand grains. It is worth noting that many of these QTLs overlap with previously identified QTLs (Manninen 2000).

The objectives of this study were to identify genetic loci controlling the traits related to yield and its components, to determine the contribution and mode of QTLs identified to the phenotypic variation in the attributes under pesticide application and non-application in the Badia $\times$ Kavir cross barley population.

\section{Materials and Methods}

\section{Plant materials and phenotypic evaluation}

In this study, $104 \mathrm{~F}_{2: 4}$ families from the Badia $\times$ Kavir cross as well as two parents were planted at the research farm of Gonbad Kavous University. The examined families were cultured using augmented design in two separate experiments (pesticide application and pesticide-free). In the pesticide-using experiment Deltamethrin, Dimethoate, Diazinon and Trichlorofon were applied for controlling pests. Barley families were planted in $0.3 \mathrm{~m}^{2}(2$ meters long rows). The distance between the plants was $25 \mathrm{~cm}$ in the rows. Peduncle length, stem diameter, flag leaf

Table 1. Chromosomal location and primer sequences of SSR markers used for linkage map.

\begin{tabular}{|c|c|c|}
\hline Marker & Chromosome & Forward / Reverse sequence \\
\hline HVM20 & 1 & CTCCACGAATCTCTGCACAA / CACCGCCTCCTCTTTCAC \\
\hline Bmag0782 & 1 & ATGTACCATTACGCATCCA / GAAATGTAGAGATGGCACTTG \\
\hline Bmac0032 & 1 & CCATCAAAGTCCGGCTAG / GTCGGGCCTCATACTGAC \\
\hline Bmag0718 & 1 & ATCGTGACATCTCAAGAACA / CCTGATACTGCCTAGCATTAG \\
\hline HVM36 & 2 & TCCAGCCGAACAATTTCTTG / AGTACTCCCACACCACGTCC \\
\hline GBM1462 & 2 & CTGTGGCTAAAGAAGGCACC / AAGATTGCTGCAGGATAGGC \\
\hline GBMS160 & 2 & ATCCAGTGGCCTTTGTATGG / TCAGCTCCTCTCTCTTCATGTG \\
\hline GBMS247 & 2 & ACACCACATTCATCTTCCTTCA / CATTGCTCTGCTTCCTGTCA \\
\hline HVM27 & 3 & GGTCGGTTCCCGGTAGTG / TCCTGATCCAGAGCCACC \\
\hline Bmag0603 & 3 & ATACCATGATACATCACATCG / GGGGGTATGTACGACTAACTA \\
\hline Bmag0225 & 3 & AACACACCAAAAATATTACATCA / CGAGTAGTTCCCATGTGAC \\
\hline Bmag0013 & 3 & AAGGGGAATCAAAATGGGAG / TCGAATAGGTCTCCGAAGAAA \\
\hline HVM67 & 4 & GTCGGGCTCCATTGCTCT / CCGGTACCCAGTGACGAC \\
\hline Cit7 & 4 & GCAGCCAAGACCTTGAGAAAGC / GCCTGAACTAGCCCGAGAAATG \\
\hline EBmac0906 & 4 & CAAATCAATCAAGAGGCC / TTTGAAGTGAGACATTTCCA \\
\hline HVM40 & 4 & CGATTCCCCTTTTCCCAC / ATTCTCCGCCGTCCACTC \\
\hline HVM30 & 5 & AGTGGGGAATGAGAGAATGG / TGCTTGTGGGGCATCACAC \\
\hline GMS001 & 5 & CTGACCCTTTGCTTAACATGC / TCAGCGTGACAAACAATAAAGG \\
\hline EBmac0684 & 5 & TTCCGTTGAGCTTTCATACAC / ATTGAATCCCAACAGACACAA \\
\hline Bmag0113 & 5 & GGAATCTTCTGGAACGTC / TTAAGAAGATCATTGTATTGAAGA \\
\hline HVM65 & 6 & AGACATCCAAAAAATGAACCA / TGGTAACTTGTCCCCCAAAG \\
\hline Bmac310 & 6 & CTACCTCTGAGATATCATGCC / ATCTAGTGTGTGTTGCTTCCT \\
\hline Bmac0040 & 6 & AGCCCGATCAGATTTACG / TTCTCCCTTTGGTCCTTG \\
\hline GBMS0083 & 6 & ACACTATACACATATAT / GAATCCCAACAGACACA \\
\hline HVM4 & 7 & AGAGCAACTACCAGTCCAATGGCA / GTCGAAGGAGAAGCGGCCCTGGTA \\
\hline GBMS0111 & 7 & ATATTTATGAAACGGTGTTCG / GGGTTTATCCTCTGCAGG \\
\hline Bmag0135 & 7 & ACGAAAGAGTTACAACGGATA / GTTTACCACAGATCTACAGGTG \\
\hline
\end{tabular}


Table 2. Sequences of ISSR, IRAP and iPBS markers used for linkage map.

\begin{tabular}{ll}
\hline Marker & Sequence \\
\hline iPBS & \\
2231 & ACTTGGATGCTGATACCA \\
2074 & GCTCTGATACCA \\
2076 & GCTCCGATGCCA \\
2415 & CATCGTAGGTGGGCGCCA \\
2221 & ACCTAGCTCACGATGCCA \\
\hline IRAP & \\
IRAP56 & TGAGTTGCAGGTCCAGGCATCA \\
IRAP54 & ACCCCTTGAGCTAACTTTTGGGTAAG \\
IRAP50 & CACTTCAAATTTTGCAGCAGCGGATC \\
\hline ISSR & \\
ISSR16 & CTCTCTCTCTCTCTCTG \\
ISSR20 & CTCTCTCTCTCTCTCT \\
ISSR22 & CTCTCTCTCTCTCTCTT \\
ISSR29 & TCTCTCTCTCTCTCTCA \\
ISSR30 & GAGGAGAGAGAGAGAG \\
\hline
\end{tabular}

length, flag leaf width, flag leaf weight, number of grains, grain weight, awn length, spike weight, and grain weight were measured for 20 plants per families and parents in both experiments.

\section{DNA and PCR extraction}

Twenty young leaves from each family were randomly selected and genomic DNA extraction was carried out using the CTAB method (Saghi Maroof et al. 1994). Horizontal gel electrophoresis (8\% agarose gel) was used to check quality of DNA. Simple Sequence Repeat (SSR), Inter Simple Sequence Repeat (ISSR), Inter Primer Binding Site (iPBS) and Inter Retrotransposon Amplified Polymorphism (IRAP) markers were used as for as providing of genetic linkage map (Table 1-2). Materials and PCR thermal program for different markers are listed in Tables 3-6.

Altogether, 28 SSR, 19 ISSR, 3 IRAP and 5 iPBS mark-

Table 3. Materials used in polymerase chain reaction for ISSR, iPBS and IRAP markers.

\begin{tabular}{lll}
\hline Components & Concentration & Amount $(\boldsymbol{\mu l})$ \\
\hline Buffer PCR10X & $1 \mathrm{X}$ & 1 \\
$\mathrm{MgCl}_{2}$ & $50 \mathrm{mM}$ & 0.48 \\
$\mathrm{dNTP}$ & $10 \mu \mathrm{l}$ & 0.6 \\
Taq DNA Polymerase Enzyme & & 0.12 \\
Primer & $60 \mathrm{ng}$ & 1.5 \\
DNA diluted & $0.75-0.5 \mathrm{ng}$ & 2.5 \\
$\mathrm{H}_{2} \mathrm{O}$ & & 3.8 \\
Final volume & & 10 \\
\hline
\end{tabular}

Table 4. Thermal program for amplification of ISSR, iPBS and IRAP markers.

\begin{tabular}{llll}
\hline Step & Temperature $\left({ }^{\circ} \mathrm{C}\right)$ & Time & Number of cycles \\
\hline Primary denaturing & 95 & $5^{\prime}$ & 1 \\
\hline Denaturing & 95 & $45^{\prime \prime}$ & \\
Annealing & - & $45^{\prime \prime}$ & 10 \\
Synthesis & 72 & $45^{\prime \prime}$ & \\
\hline Denaturing & 95 & $45^{\prime \prime}$ & \\
Annealing & - & $45^{\prime \prime}$ & 25 \\
Synthesis & 72 & $45^{\prime \prime}$ & \\
\hline Final amplification & 72 & $5^{\prime}$ & 1 \\
\hline
\end{tabular}

ers (93 alleles) were used to determine the genotype on the studied population. After the PCR reaction, amplified DNA was electrophoresed on 6\% polyacrylamide gel. Fast silver nitrate method (An et al. 2009; Byum et al. 2009) was used for visualization of the gel.

\section{Statistical analysis}

Map Manager QTX17 software (Manley and Olson 1999) was used for genetic mapping and MapChart software (Voorrips 2002) for drawing of map. The point that had the highest LOD value was identified as the region most likely to have QTL. The critical limit for detecting QTLs was obtained by the permutation test $(\mathrm{LOD}=2)$. The exact position of the QTL relative to both markers was determined in cM. QTLs were named according to the method of McCouch et al. (1997). First, the letter $q$ and then the trait abbreviation was capitalized and separated using a dash from the chromosome number on which the QTL was identified. It is worth noting that the mean of each family was used for each trait in the QTL analysis. QTL was analyzed using QGene software (Nelson 1997).

\section{Results}

The phenotypic distributions of barley studied traits width in the $\mathrm{F}_{2: 4}$ populations grown in the using and no using pesticides environments are shown in Fig. 1. Means of traits among parents was significant for all traits in both of condition except shoot thickness. The genotypes in the $\mathrm{F}_{2: 4}$ population differed significantly $(\mathrm{P}<0.05)$ for all traits (Table 7), indicating the presence of sufficient genetic variation. In all traits, $\mathrm{F}_{2: 4}$ progeny was observed that fell beyond the high or low mean of the two parents (Fig. 1-2). For all characters, the number of observed extreme individuals significantly $(\mathrm{P}<0.01)$ exceeded the expected, suggesting transgressive segregation.

A genetic linkage map was generated using 28 SSR markers, 19 ISSR markers, 3 IRAP markers, and 5 iPBS 
Bakhtiari et al.

Table 5. Materials used in polymerase chain reaction for SSR markers.

\begin{tabular}{lll}
\hline Components & Concentration & Amount $(\boldsymbol{\mu l})$ \\
\hline Buffer PCR10X & $1 \mathrm{X}$ & 1 \\
$\mathrm{MgCl}_{2}$ & $50 \mathrm{mM}$ & 0.48 \\
$\mathrm{dNTP}$ & $10 \mathrm{mM}$ & 0.6 \\
Taq DNA Polymerase Enzyme & & 0.12 \\
Forward primer & $60 \mathrm{ng}$ & 0.75 \\
Reverse primer & $60 \mathrm{ng}$ & 0.75 \\
Diluted DNA & $0.75-0.5 \mathrm{ng}$ & 2.5 \\
$\mathrm{H}_{2} \mathrm{O}$ & & 3.8 \\
Final volume & & 10 \\
\hline
\end{tabular}

Table 6. Thermal program for amplification of SSR markers.

markers (93 alleles) as well as $104 \mathrm{~F} 2$ individuals. The markers used were divided into 7 linkage groups corresponding to 7 barley chromosomes. Based on the Kosambi's mapping function (Kosambi 1994), the map length was estimated to be $617.5 \mathrm{cM}$ and the average marker interval was $5.41 \mathrm{cM}$ (Fig. 3).

A total of 25 QTLs were mapped for traits. The minimum and maximum LODs were detected in the range of 2.038-4.537 for awn length and flag leaf length. The explained variance for traits in both conditions varied from 8.7 to 16.1 (Table 8 ).

In pesticide-free condition, 12 QTL were identified for peduncle length, stem diameter, flag leaf length, awn

\begin{tabular}{llll}
\hline Step & Temperature $\left(^{\circ} \mathrm{C}\right)$ & Time & Number of cycles \\
\hline Primary denaturing & 94 & $5^{\prime}$ & 1 \\
\hline Denaturing & 94 & 1 & \\
Annealing & 64 & $30^{\prime \prime}$ & 18 \\
Synthesis & 72 & $1^{\prime}$ & \\
\hline Denaturing & 72 & $1^{\prime}$ & \\
Annealing & 94 & $1^{\prime}$ & 30 \\
Synthesis & 55 & $1^{\prime}$ & \\
\hline Final amplification & 72 & $5^{\prime}$ & 1 \\
\hline
\end{tabular}

length and Peduncle length. qPL-3, in ISSR13-3-ISSR47-8 marker interval at position of $48 \mathrm{cM}$ accounted for $9.2 \%$ of the total variation of peduncle length. Five QTLs controlled stem diameter (qSD-1, qSD-4a, arise-4b, qSD-6, qSD-7) at positions of 70, 0, 72.0, and $0 \mathrm{cM}$ in ISSR47-1, ISSR31-6, ISSR 20-1, ISSR38-6, ISSR48-1 flanked markers, that increased stem diameter with an additive effect from Badia. Three QTLs were identified at position 10, 68, 0 near Bmag0013, ISSR31-5, and ISSR31-6 markers for flag leaf length accounting for 11.5, 11.8, and 18.4\% of the phenotypic variation, respectively (Fig. 4). For awn length, three QTLs (qRL-2a, qRL-3a, qRL-3b) on chromosomes 2 and 3 could account for about $29.3 \%$ of the total variation of this trait at positions 76,2 , and 68 .
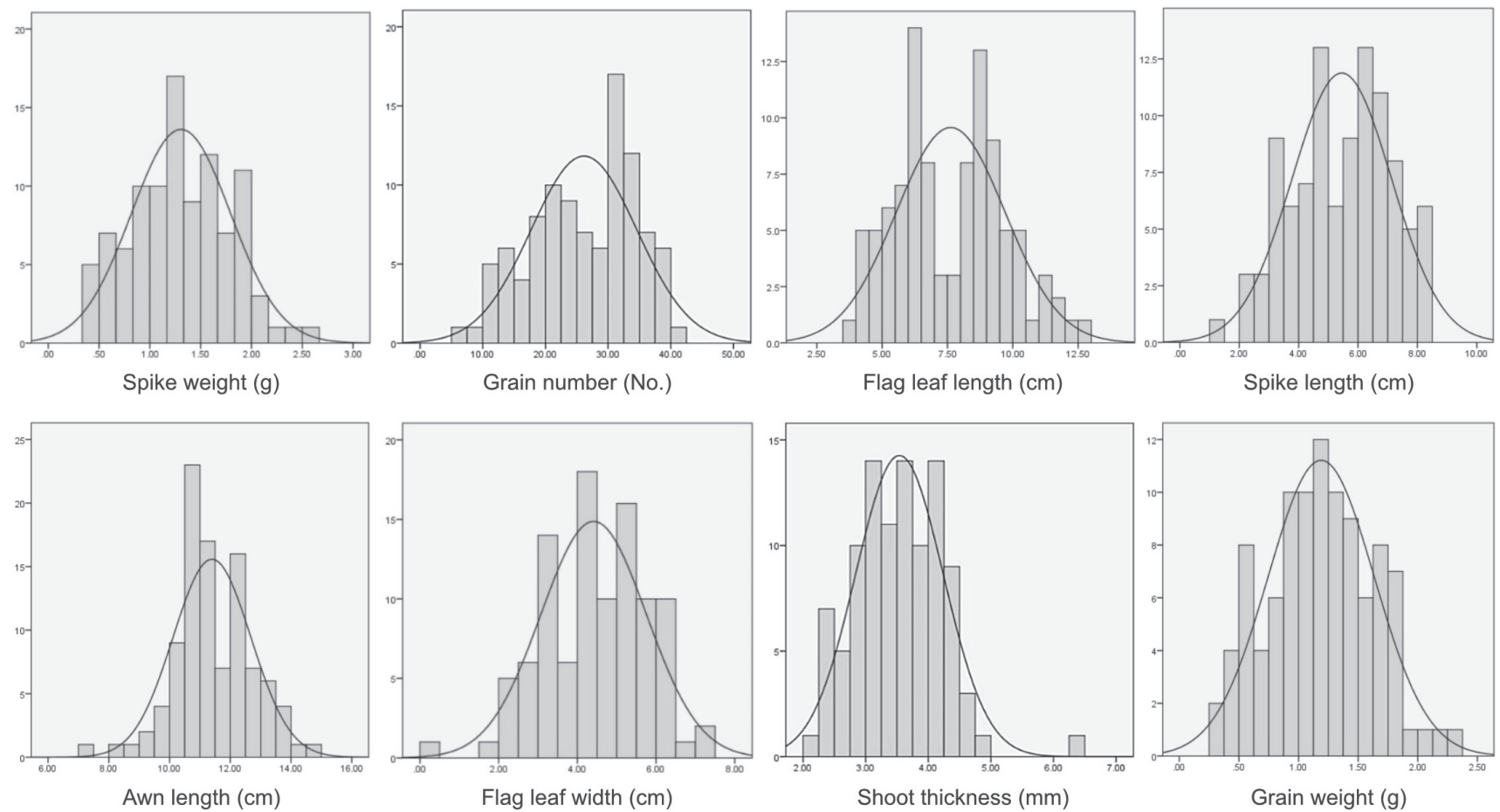

Figure 1. The histogram of studied traits in population where pesticides were not used. 


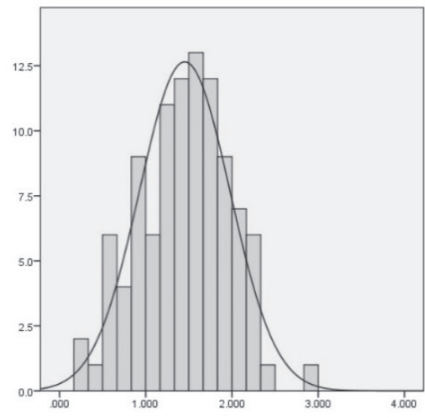

Spike weight $(\mathrm{g})$

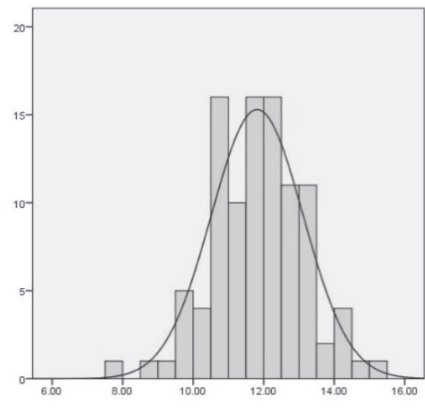

Awn length $(\mathrm{cm})$

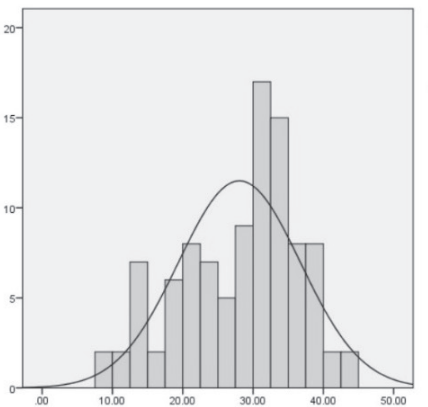

Grain number (No.)

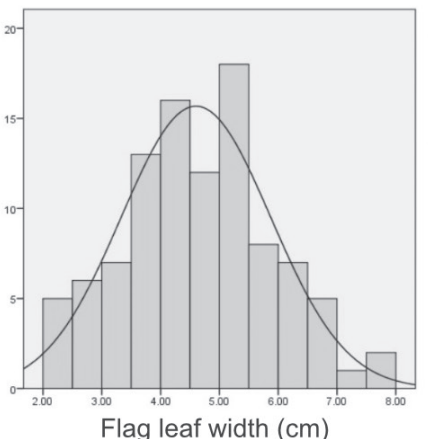

Flag leaf width $(\mathrm{cm})$

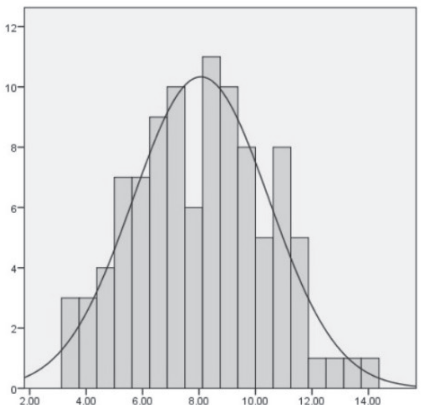

Flag leaf length $(\mathrm{cm})$

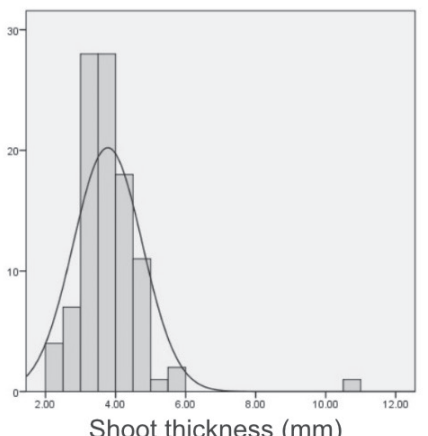

Shoot thickness $(\mathrm{mm})$

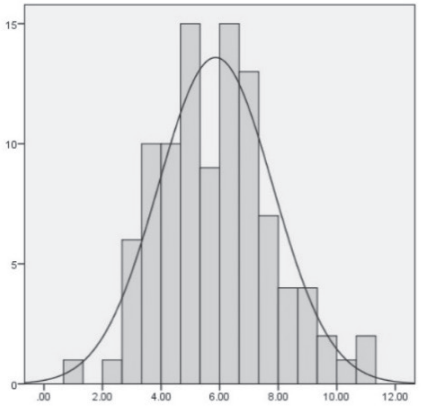

Spike length $(\mathrm{cm})$

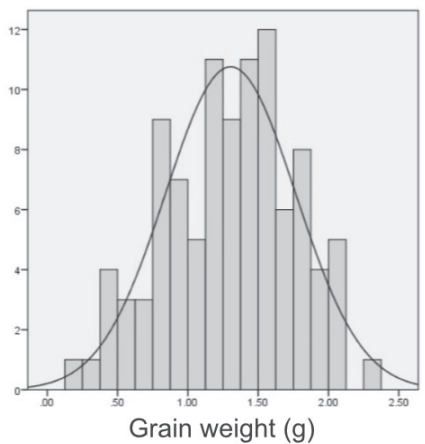

Figure 2. The histogram of studied traits in pesticide-treated population.

From these QTLs, qPL-3 was found to have major effects $\left(\mathrm{R}^{2}=11.8\right)$.

In pesticide-treated population, 13 QTLs were detected. For stem diameter, three QTLs (qSD-3, qSD-6a, qSD-6b) were detected on chromosomes 3, 6 (two QTLs) at positions 48, 2, and $18 \mathrm{cM}$ in ISSR13-3 - ISSR47-8, ISSR38-6-Bmac310, and IRAP50-3-ISSR48-3 marker intervals. The stem diameter was found to have major effects, accounting for 10.9 and $16.5 \%$ of the phenotypic variation, respectively. For flag leaf length, 3 QTLs (qFL-3, qFL-7a, and qFL-7b) were identified on chromosomes 3 , 7 (two QTLs) at positions 48, 102, and 106. For flag leaf width, qWI- 6 at position $52 \mathrm{cM}$ flanked by HVM65Bmac0040 markers and was located with an LOD of 2.16. This QTL allele was transferred from Kavir with a negative additive effect.

For flag leaf weight, one QTL (qFWE-4) was identified at $2 \mathrm{cM}$ from the beginning of the chromosome at

Table 7. Means comparison of parents for agronomically traits in no using pesticides and using pesticides.

\begin{tabular}{|c|c|c|c|c|c|c|}
\hline \multirow{2}{*}{ Traits } & \multicolumn{3}{|c|}{ Without pesticides } & \multicolumn{3}{|c|}{ Treated with pesticides } \\
\hline & Kavir & Badia & T-test & Kavir & Badia & T-test \\
\hline Biomass (g) & 126.378 & 149.077 & ** & 95.632 & 116.321 & ** \\
\hline Spike weight per plant (g) & 34.421 & 51.746 & $* *$ & 27.632 & 46.325 & ** \\
\hline Spike number per plant & 34.000 & 45.000 & ** & 26.000 & 33.000 & ** \\
\hline Spike length (cm) & 99.000 & 110.000 & $* *$ & 86.215 & 98.784 & ** \\
\hline Grain yield per plant (g) & 43.297 & 63.526 & ** & 32.125 & 54.369 & ** \\
\hline Peduncle length (cm) & 3.000 & 6.420 & ** & 2.690 & 5.632 & ** \\
\hline Shoot thickness (mm) & 4.100 & 4.480 & ns & 2.652 & 2.832 & ns \\
\hline Flag leaf length (cm) & 11.300 & 9.900 & ** & 8.321 & 7.954 & ** \\
\hline Flag leaf weight (g) & 0.140 & 0.020 & ** & 0.122 & 0.018 & ** \\
\hline Grain number & 34.000 & 36.000 & * & 26.000 & 31.000 & * \\
\hline Grain weight (g) & 1.340 & 1.820 & ** & 1.126 & 1.325 & * \\
\hline Awn length (cm) & 12.360 & 10.400 & * & 11.635 & 9.847 & ** \\
\hline
\end{tabular}


1

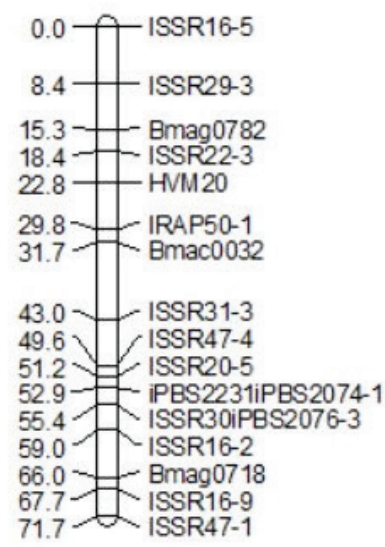

2

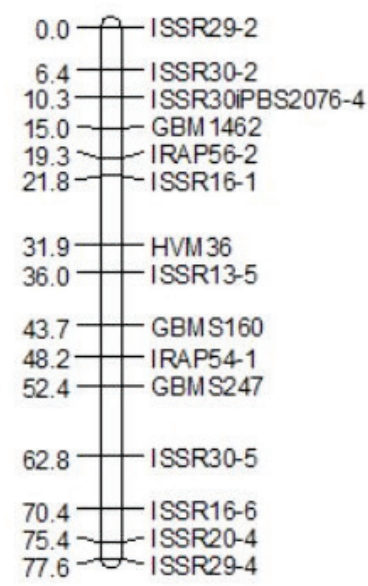

3

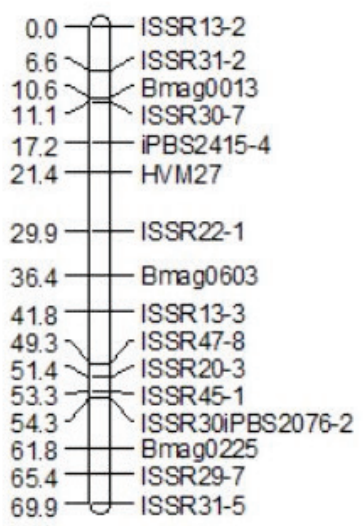

4

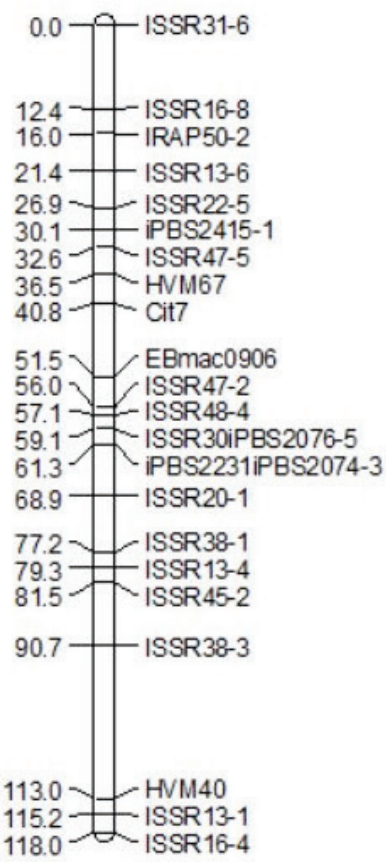

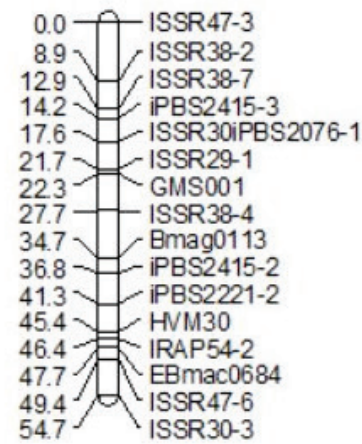

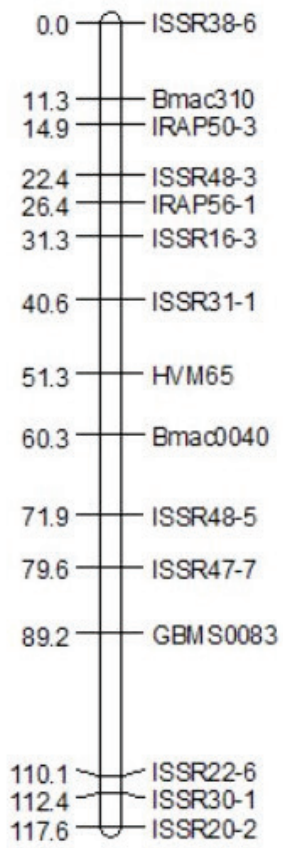

7

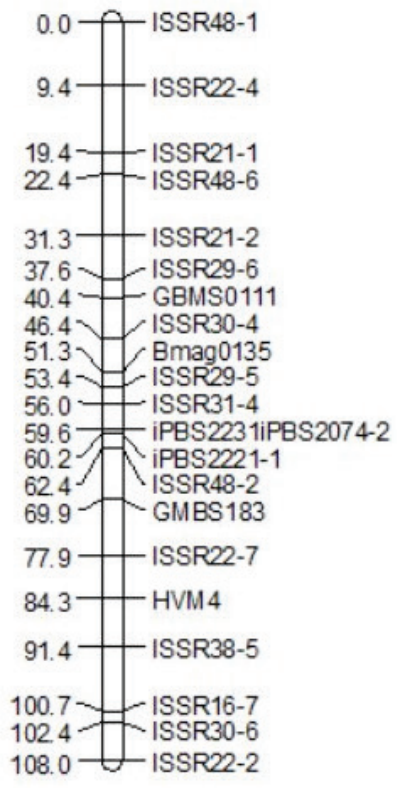

Figure 3. Linkage map caused Badia $\times$ Kavir cross based on 28, 9, 3 and 5 SSR, ISSR, IRAP and iPBS markers in F2:4 mapping population.

ISSR31-6-ISSR16-8 marker interval and LOD of 3.935 and phenotypic variance of 16.1 with a negative additive effect of Kavir. qSN-3 at $48 \mathrm{cM}$ flanked by ISSR13-3ISSR 47-8 markers with an LOD of 2.213 accounted for $9.4 \%$ of the variation in grain number. For spike weight, one QTL was detected on chromosome 3 at $48 \mathrm{cM}$ above the chromosome (Fig. 5). This QTL was within the ISSR133-ISSR 47-8 marker interval and accounted for 13.2\% of the variation with an LOD of 3.163. For grain weight, 3 QTLs (qSW-1a, qSW-1b, qSW-3) were identified that could account for $12.8,12.8$, and $15.7 \%$, respectively, and had a positive additive effect for this trait at chromosomes 64 , 
Table 8. QTL detected for agronomical traits in F2:3 caused Badia $\times$ Kavir populations.

\begin{tabular}{|c|c|c|c|c|c|c|c|c|}
\hline Trait & QTL & Chromosome & Position & Flanking marker & LOD & Additive & $\mathrm{R}^{2}$ & Allele direction \\
\hline \multicolumn{9}{|c|}{ Without pesticides } \\
\hline & qPLNUF-3 & 3 & 48 & ISSR13-3- ISSR47-8 & 2.158 & -0.813 & 9.2 & Kavir \\
\hline & qSTNUF-1 & 1 & 70 & ISSR16-9-ISSR47-1 & 2.911 & -0.713 & 12.2 & Kavir \\
\hline & qSTNUF-4a & 4 & 0 & ISSR31-6- ISSR16-8 & 2.289 & 0.581 & 9.7 & Badia \\
\hline & qSTNUF-4b & 4 & 72 & ISSR20-1-ISSR38-1 & 2.240 & -0.583 & 9.5 & Kavir \\
\hline & qSTNUF-6 & 6 & 0 & ISSR38-6-Bmac310 & 2.478 & 0.580 & 10.5 & Badia \\
\hline & qSTNUF-7 & 7 & 0 & ISSR48-1-ISSR22-4 & 2.041 & -0.437 & 8.7 & Kavir \\
\hline & qFLLNUF-3a & 3 & 10 & ISSR31-2- Bmag0013 & 2.745 & -0.605 & 11.5 & Badia \\
\hline & qFLLNUF-3b & 3 & 68 & ISSR29-7-ISSR31-5 & 2.806 & 0.949 & 11.8 & Kavir \\
\hline & qFLLNUF-4 & 4 & 0 & ISSR31-6- ISSR16-8 & 4.537 & 1.235 & 18.4 & Kavir \\
\hline & qALNUF-2 & 2 & 76 & ISSR20-4 - ISSR29-4 & 2.038 & -1.432 & 8.7 & Badia \\
\hline & qALNUF-3a & 3 & 2 & ISSR13-2 - ISSR31-2 & 2.072 & -1.688 & 8.8 & Badia \\
\hline & qALNUF-3b & 3 & 68 & ISSR29-7 - ISSR31-5 & 2.802 & -0.707 & 11.8 & Badia \\
\hline \multicolumn{9}{|c|}{ Treated with pesticides } \\
\hline & qSTUF-3a & 3 & 48 & ISSR13-3 - ISSR47-8 & 2.57 & -2.961 & 10.9 & Badia \\
\hline & qSTUF-6a & 6 & 2 & ISSR38-6 - Bmac310 & 4.025 & -1.71 & 16.5 & Badia \\
\hline & qSTUF-6b & 6 & 18 & IRAP50-3 - ISSR48-3 & 2.303 & -1.949 & 9.8 & Badia \\
\hline & qFLLUF-3 & 3 & 48 & ISSR13-3 - ISSR47-8 & 2.2 & -4.632 & 9.4 & Kavir \\
\hline & qFLLUF-7a & 7 & 102 & ISSR16-7- ISSR30-6 & 2.544 & 1.551 & 10.8 & Badia \\
\hline & qFLLUF-7b & 7 & 106 & ISSR30-6-ISSR22-2 & 2.413 & 2.525 & 10.2 & Badia \\
\hline & qFLWIUF-6 & 6 & 52 & HVM65- Bmac0040 & 2.16 & -0.672 & 9.2 & Kavir \\
\hline & qFLWEUF-4 & 4 & 2 & ISSR31-6- ISSR16-8 & 3.935 & 0.194 & 16.1 & Badia \\
\hline & qGNUF-3 & 3 & 48 & ISSR13-3-ISSR47-8 & 2.213 & -11.546 & 9.4 & Kavir \\
\hline & qGWUF-1a & 1 & 64 & ISSR16-2- Bmag0718 & 3.06 & 0.272 & 12.8 & Badia \\
\hline & qGWUF-1b & 1 & 66 & Bmag0718-ISSR16-9 & 3.057 & 0.218 & 12.8 & Badia \\
\hline & qGWUF-3 & 3 & 48 & ISSR13-3- ISSR47-8 & 3.809 & -0.944 & 15.7 & Kavir \\
\hline & qSWUF-3 & 3 & 48 & ISSR13-3- ISSR47-8 & 3.163 & -0.945 & 13.2 & Kavir \\
\hline
\end{tabular}

66, 48 cM in ISSR16-2-Bmag0718, Bmag0718-ISSR16-9, and ISSR13-3-ISSR47-8 marker intervals (Fig. 6).

To identify and map the dwarfism gene in 92 double haploid barley lines and its correlation with agronomical traits, Wang et al. (2010) identified two QTLs for spike emergence, two QTLs for spike length, one QTL for grain number, and one QTL for awn length on chromosome H3, which accounted for $70-81 \%$ of the relevant phenotypic variance of the trait. The results of Wang et al.'s (2010) work on chromosome \#3 were consistent for awn length and grain number traits. In addition, Teulat et al. (2001a,b) identified two QTLs on chromosomes 3 and 4. The results of this study on chromosome $\# 3$ are consistent with the results of Teulat et al. (2001 a,b).

\section{Discussion}

The widespread use of various pesticides, including herbicides, insecticides, fungicides, and rodenticides, has long been a cause for concern for environmental pollu- tion and endangering human health. Adverse effects of these compounds on living and non-living environment include accumulation and concentration of pesticides in the living body and entry into the food chain, and long-

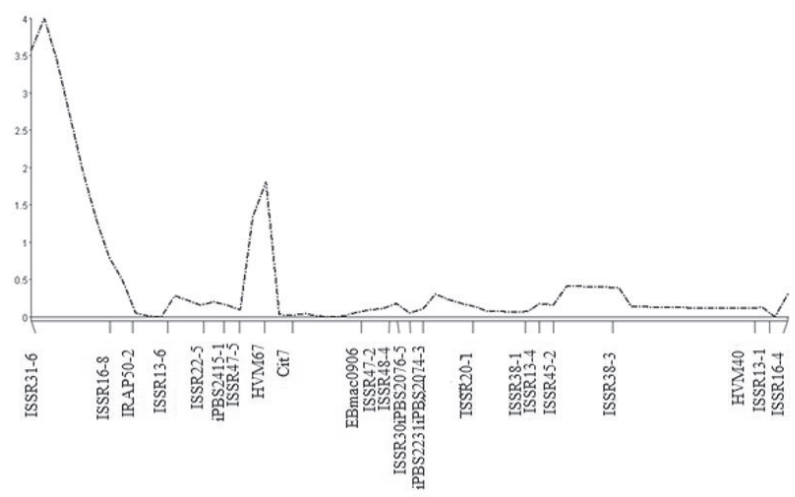

Figure 4. QTL mapping result for flag leaf length (on chromosome 3) in population where pesticides were not used. 


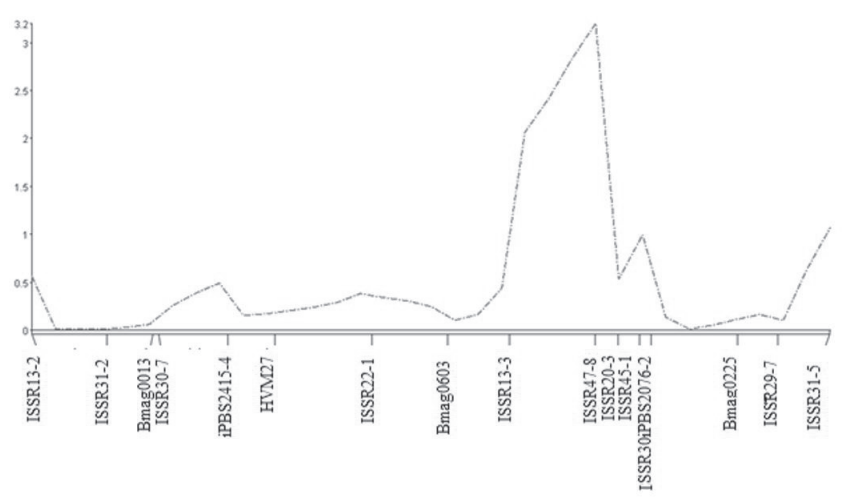

Figure 5. QTL mapping result for spike weight (on chromosome 3) in pesticide-treated population.

term contamination of water and soil resources with pesticides and their residues (Shaw et al. 1992; Newman 2008). The development of pesticide resistance in pest populations could increase with the elevated concentration of these compounds as well as with repeated applications (Hemingway and Ranson 2000; Brown and Pal 1971; Hemingway et al. 1992). The combination of different control methods, including environmental, biological,
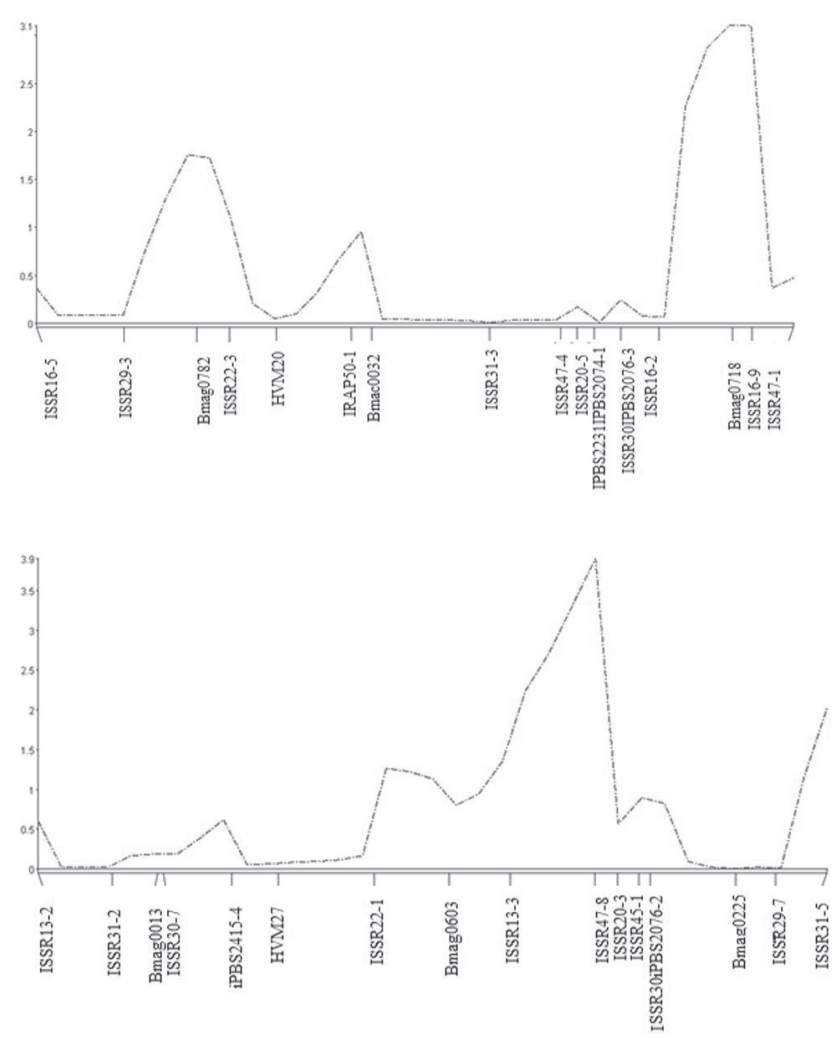

Figure 6. QTL mapping result for grain weight (on chromosome 1 and 3) in pesticide-treated population. genetic, and chemical approaches, has been able to reduce environmental pollution and at the same time properly controls population of harmful pests.

This study sought to investigate the effect of pesticide application on the emergence and absence of QTLs in attribute controllers in barley. To do this, first a genetic map with molecular markers was developed. The obtained linkage map showed that the distribution of markers on linkage groups was not uniform and the highest number of markers belonged to linkage group \#3 and the lowest number of markers to linkage group \#5 (Fig. 3). Since the resulting map length was $617.5 \mathrm{cM}$ and the interval between the two flanking markers was $5.41 \mathrm{cM}$, the resulting map was found to be suitable for gene mapping (Fig. 1).

The study identified 25 QTLs. Comparison of QTLs detected under both conditions, namely pesticide application and non-application showed that some chromosome regions play an effective role in controlling attributes under both conditions. For example, in ISSR13-3-ISSR47-8 and ISSR38-6-Bmac310 marker intervals, QTLs related to stem diameter, peduncle length, flag leaf length, and seed weight, were detected under both conditions; however, some regions played a role only in the absence of pesticide use, IRAP50-3-ISSR48-3, HVM65-Bmac0040. Therefore, it can be concluded that pesticide application is effective in the presence or absence of some genes in barley. The major-effect trait-controller QTLs concerned, and their associated markers can be used in MAS programs. The results showed that when plant populations are treated with pesticides, the expression of genes controlling traits is affected.

\section{Acknowledgments}

Samira Bakhtiari and the co-authors acknowledge the Research Deputy of Gonbad Kavous University for providing funding to complete this work.

\section{References}

An ZW, Xie LL, Cheng H, Zhou Y, Zhang Q, He XG (2009) A silver staining procedure for nucleic acids in polyacrylamide gels without fixation and pretreatment. Anal Biochem 391(1):77-79.

Ayoub M, Armstrong E, Bridger G, Fortin MG, Mather DE (2003) Marker-based selection in barley for a QTL region affecting alpha amylase activity of malt. Crop Sci 43:556-561.

Bonnechère $\mathrm{A}$, Hanot $\mathrm{V}$, Jolie R, Hendrickx $\mathrm{M}$, Bragard $\mathrm{C}$, Bedoret T (2012) Effect of household and industrial processing on levels of five pesticide residues and two deg- 
radation products in spinach. Food Control 25:397-406.

Brown AWA, Pal R (1971) Insecticide resistance in arthropods. World Health Organization monograph series 2nd ed. 38:95-143.

Byum SO, Fang Q, Zhou H, Hickford JG (2009) An effective method for silver-staining DNA in large numbers of polyacrylamide gels. Anal Biochem 385(1):174-175.

Feug ZY, Liu XJ, Zhang YZ, Ling HQ (2006). Genetic diversity analysis of Tibetan wild barley using SSR markers. Acta Genet Sin 33:917-928.

Germán S, Arbelbide M, Abadie T, Romero R, Peculio A (2000) Characterization of photoperiod response of barley genotypes from diverse origin. In Logue S, ed., Barley Genetics VIII, Vol. III.-Contributed Papers. Glen Osmond, Adelaide University. p. 212-214

Han F, Ullrich SE (1994). Mapping of quantitative trait loci for malting quality traits in barley. Barley Genet Newsl 23:84-97.

Hassan M, Oldach K, Baumann U, Langridge P, Sutton T (2010) Genes mapping to boron tolerance QTL in barley identified by suppression subtractive hybridization. Plant Cell Physiol 33:118-198.

Hemingway J, Ranson H (2000) Insecticide resistance in insect vectors of human disease. Annu Rev Entomol 45:371-391.

Hemingway J, Small GJ, Monro A, Sawyer BV, Kasap H (1992) Insecticide resistance gene frequencies in Anopheles sacharovi populations of the Cukurova plain, Adana province, Turkey. Med Vet Entomol 6:342-348.

Kandemir N, Jones BL, Wesenberg DM, Ullrich SE, Kleinnofs A (2000) Marker-assisted analysis of three grain yield QTL in barley using near isogenic lines. Mol Breed 6:157-167.

Kaushik G, Satya S, Naik SN (2009) Food processing a tool to pesticide residue dissipation- A review. Food Res Int 42:26-40.

Kosambi DD (1994) The estimation of map distance from recombination values. Ann Eugen 12:172-175.

Landjeva S, Lohwasser U, Borner A (2010) Genetic mapping within the wheat D genome reveals QTL for germination, seed vigour and longevity, and early seedling growth. Euphytica 171:129-143.

Li JZ, Huang XQ, Heinrichs F, Ganal M, Roder MS (2005) Analysis of QTLs for yield, yield components, and malting quality in a BC3-DH population of spring barley. Theor Appl Genet 110:356-363.

Manly KF, Olson JM (1999) Overview of QTL mapping software and introduction to Map Manager QTL. Mamm Genome 10:327-334.

Manninen O (2000) Genetic mapping of traits important in barley breeding. Acad Dissert, Univ Helsinki, Helsingin yliopiston verkkojulkaisut, Helsinki.

McCouch SR, Cho YG, Yano M, Paul E, Blinstrub M (1997)
Report on QTL nomenclature. Rice Genet Newsl 14:1113.

Nelson JC (1997) QGENE: software for marker-based genomic analysis and breeding. Mol Breed 3(3):239-245.

Newman MC, Clements WH (2008) Ecotoxicology: A Comprehensive Treatment. CRC Press, USA. p. 880.

Saghi Maroof MA, Biyaoshev RM, Yang GP, Zhang Q, Allard RW (1994) Extra ordinarily polymorphic microsatellites DNA in barley species diversity, chromosomal location, and population dynamics. Proc Natl Acad Sci USA 91:4566-5570.

Shaw IC, Chadwick J (1992) Principles of Environmental Toxicology. Taylor \& Francis, London, Bristol, PA. p. 216.

Shibamoto T, Bjeldanes LF (2009) Introduction to Food Toxicology. 2nd ed. Elsevier, p. 320.

Shokrzadeh M, Saravi SSS (2011) Pesticides in agricultural products: analysis, reduction, prevention. In Stoytcheva M, Ed., Pesticides-formulations, Effects, Fate. InTech, India, p. 225-242.

Teulat B, Merah O, Souyris I, This D (2001a) A new QTLs identified for plant water-status, water-soluble carbohydrate and osmotic adjustment in a barley population grown in a growth-chamber under two water regimes. Theor Appl Genet 103:16-170.

Teulat B, Merah O, Souyris I, This D (2001b) QTLs for agronomic traits from a Mediterranean barley progeny grown in several environments. Theor Appl Genet 103:774-787.

Voorrips RE (2002) Map chart: software for the graphical presentation of linkage maps and QTLs. J Hered 93(1):77-78.

Wang J, Yang J, McNeil DL, Zhou M (2010) Identification and molecular mapping of a dwarfing gene in barley (Hordeum vulgare L.) and its correlation with other agronomic traits. Euphytica 175:331-342.

Zong-Yun F, Xian-Jun L, Yi-Zhang Z, Hong-Qing L (2006) Genetic diversity analysis of Tibetan wild barley using SSR marker. Acta Genet Sin 33:917-923. 
